\title{
Splenic size after division of the short gastric vessels in Nissen fundoplication in children
}

\author{
C. Driessen • G. F. Paulus • S. G. Robben • \\ W. E. Tjon a Ten $\cdot$ A. Van den Neucker . \\ B. H. Verhoeven • L. W. E. Van Heurn
}

Accepted: 14 November 2011 / Published online: 30 November 2011

(C) The Author(s) 2011. This article is published with open access at Springerlink.com

\begin{abstract}
Purpose Nissen fundoplication is an effective treatment for gastro-esophageal reflux disease (GERD). Mobilization of the gastric fundus during fundoplication requires division of short gastric vessels of the spleen, which may cause splenic ischemia. The aim of this study was to determine if Nissen fundoplication results in hypotrophy of the spleen. Methods We performed pre-operative and post-operative ultrasound measurements of the spleen in children undergoing Nissen fundoplication. During operation, the surgeon estimated the compromised blood flow by assessment of the percentage of discoloration of the spleen.

Results Twenty-four consecutive children were analyzed. Discoloration of the upper pole of the spleen was observed in 11 patients $(48 \%)$ of a median estimated splenic surface of $20 \%$ (range 5-50\%). The median ratio for pre-operative and post-operative length, width, and area of the spleen was $0.97,1.03$, and 0.96 , respectively. The percentage of the estimated perfusion defect during surgery was not
\end{abstract}

C. Driessen $(\bowtie)$ · G. F. Paulus · B. H. Verhoeven .

L. W. E. Van Heurn

Department of General Surgery, Maastricht University Medical

Centre, P.Debyelaan 25, 6202 Maastricht, The Netherlands

e-mail: cdriessen@gmail.com

S. G. Robben

Department of Radiology, Maastricht University Medical

Centre, Maastricht, The Netherlands

W. E. Tjon a Ten · A. Van den Neucker

Department of Pediatric Gastroenterology, Maastricht University

Medical Centre, Maastricht, The Netherlands

W. E. Tjon a Ten

Department of Pediatrics, Maxima Medical Center,

Veldhoven, The Netherlands correlated with the ratios. In three patients, the area ratio was smaller than $0.8(0.67-0.75)$, meaning that the area decreased with at least $20 \%$ after surgery. In none of these patients a discoloration was observed.

Conclusion Discoloration of the spleen after Nissen fundoplication is not associated with post-operative splenic atrophy.

Keywords Fundoplication - Gastrointestinal reflux · Pediatrics · Short gastric vessels · Spleen · Ultrasound

\section{Introduction}

Nissen fundoplication is an effective treatment for gastroesophageal reflux disease (GERD). It has also been popularized in children and presently, it is the second most common pediatric surgical procedure in the United States [1-3]. To ensure a floppy wrap of the fundus of the stomach to minimize dysphagia and residual gastro-esophageal reflux, many advocate to divide the short gastric vessels during operation [4-7]. Although the spleen is extensively vascularized by the splenic artery, division of the gastric vessels often results in perfusion defects of the spleen. It is unknown how often it occurs and whether it results in clinically relevant hypotrophy of the spleen $[8,9]$.

The spleen is essential for optimal immunologic function. If the splenic mass is reduced with $50-70 \%$, there is an increased risk of infection, particularly of overwhelming streptococcal septicemia with a high mortality [10, 11]. Death due to septicemia after a vanishing spleen after Nissen fundoplication has been described [12]. Therefore, we assessed the effect of division of the short gastric splenic vessels during Nissen fundoplication on the size of the spleen. 


\section{Materials and methods}

The size of the spleen was measured ultrasonographically before and after surgery in children aged 15 years or younger, who underwent a laparoscopic Nissen fundoplication between March 2007 and December 2010. Excluded from the study were children with open surgery and children in whom a second ultrasound was not considered feasible because of long travel distances. The patients were suffering from gastro-esophageal reflex disease which did not sufficiently respond to medical therapy. All procedures were performed by two experienced and specialized pediatric surgeons (BV and $\mathrm{LvH}$ ) and the operating technique was similar in all the patients: the tissue between the posterior portion of the stomach and the left diaphragmatic crus was dissected free and the distal esophagus and proximal stomach were mobilized. The superior pole of the spleen was separated from the gastric fundus which required division of the short gastric vessels in all the patients. The part of the spleen that became ischemic was estimated by the surgeon as a percentage of the discoloration and registered.

Pre-operatively and at least 3 months post-operatively, the size of the spleen was measured ultrasonographically (iU22, Philips Health Care, Bothell, WA, USA) by an expert pediatric radiologist (SGR) using a $4-9 \mathrm{MHz}$ broadband curved array transducer. The length, width and area of the spleen, defined as the section of the spleen in the position with the largest diameters, were determined at their maximal dimension. The ratio of the splenic size was, calculated by dividing the post-operative value by the preoperative value, so that a ratio less than 1 means a decrease in size.

Data are listed as median (range) and were analyzed using IBM SPSS Data editor 16. Non-parametric tests were used to analyze the paired measurements (Wilcoxon signed ranks test) and correlation of ischemic coloring and age and size ratio (Spearman's correlation). A predictive value smaller than 0.05 was considered to be statistically significant.

\section{Results}

Twenty-seven patients underwent a laparoscopic Nissen fundoplication in the study period. Three patients were not willing to participate to the study due to travel distance. Twenty-four children entered the study; one patient was excluded from analysis because the spleen could not be visualized ultrasonographically. In this patient the spleen was found in the left lower quadrant of the abdominal cavity at operation. The characteristics of the 23 analyzed patients are shown in Table 1.
Table 1 Patient characteristics of 23 analyzed patients

\begin{tabular}{ll}
\hline Patient characteristic & \\
\hline Number of patients & 23 \\
Age at surgery (years) & $2(0-14)$ \\
Sex (m:f) & $14: 9$ \\
Mentally handicapped $(n)$ & 5 \\
\hline
\end{tabular}

Table 2 Ultrasound measurements of the spleen

\begin{tabular}{lccc}
\hline Parameter & Length $(\mathrm{cm})$ & Width $(\mathrm{cm})$ & Area $\left(\mathrm{cm}^{2}\right)$ \\
\hline Pre & 7.3 & 3.1 & 22.8 \\
& $(5.1-12.0)$ & $(1.7-6.7)$ & $(10.1-68.3)$ \\
Post & 6.5 & 3.1 & 22.1 \\
& $(5.3-13.0)$ & $(2.2-6.9)$ & $(13.4-61.4)$ \\
Paired measurement & $Z=-1.00$ & $Z=-0.73$ & $Z=-0.46$ \\
pre and post & $p=0.47$ & $p=0.31$ & $p=0.65$ \\
Ratio & 0.97 & 1.03 & 0.96 \\
& $(0.83-1.57)$ & $(0.70-1.52)$ & $(0.67-2.02)$ \\
Correlation with per- & $R=-0.087$ & $R=-0.003$ & $R=0.087$ \\
$\begin{array}{l}\text { operative ischemic } \\
\text { decolorization }\end{array}$ & $p=0.69$ & $p=0.99$ & $p=0.70$ \\
\hline
\end{tabular}

Pre-operative and post-operative ultrasound measurements of the spleen in 23 cases. Data are presented as median (range)

In 11 patients (48\%) there was discoloration of the upper pole of the spleen during surgery with a median estimated splenic surface of $20 \%$ (range 5-50\%). Post-operatively, there were no patients with left upper abdominal pain, fever or chill as symptoms of splenic infarction.

At ultrasound at a median of 3 months after operation (range 2-27, seven patients after 6 months or longer) there were no patients with clinically relevant hypotrophy of the spleen. The median pre- and post-operative length, width, and area are listed in Table 2. There were no significant changes in splenic size before and after surgery: the median ratio for pre-operative and post-operative length, width, and area was $0.97,1.03$, and 0.96 , respectively.

The percentage of the estimated perfusion defect during surgery was not correlated with the measured length, width, or area ratio (Table 2). In three patients, the area ratio was smaller than $0.8(0.67-0.75)$, at 3.3 and 7 months follow-up, meaning that the area decreased with at least $20 \%$ after surgery. In none of these patients there was any discoloration of the spleen during surgery. In five patients the area ratio was 1.2 or more. Three of these measurements were taken more than 6 months after fundoplication. There was a significant correlation of the patients age with the pre-operative size of the spleen $(R=0.55, p=0.007$ for length; $R=0.52, p=0.012$ for width; and $R=0.60$, $p=0.003$ for area). Age was not significantly correlated 
with the pre and post-operative ratio of length, width and area; therefore, decrease in splenic size was not agedependant $(R=0.12, p=0.59$ for length; $R=-0.38$, $p=0.08$ for width; and $R=-0.28, p=0.19$ for area).

\section{Discussion}

Gastro-esophageal reflux disease is relatively common in children [1-3]. Fundoplication has shown to be a successful and safe treatment in children with severe GERD or in children in whom medical therapy is ineffective [2, 13-15]. There are several surgical techniques to treat GERD, of which Nissen fundoplication is the most frequently used. There is no common opinion as to whether the short gastric vessels should be divided to obtain an adequate wrap in Nissen fundoplication [4, 5]. In adults, there is evidence that division of the short gastric vessels has no additional effect on reflux control $[6,7]$. In children, the fundus of the stomach is smaller, and the stomach is closely attached to the spleen. Moreover, particularly in young or disabled children, dysphagia due to a tight wrap is more difficult to handle [16, 17].

It is extremely important to preserve the spleen during surgery, since it has an important function as secondary lymphoid organ in immune defense and bloodstream filter $[10,11,18]$. Asplenia is related with an increased risk of bacteremia, especially after infection with encapsulated bacteria including $S$. pneumoniae, $H$. influenzae type b and $N$. meningitidis $[10,18]$. After splenectomy, life-threatening infections occur with a lifetime risk of 5\% and an estimated incidence of $0.23-0.42 \%$ per year [18]. The risk of infection is highest in young children and during the first 2 years after the spleen has been lost [18]. To reduce the chance of infection, vaccination and prophylactic antibiotic treatment is recommended. This reduces, but does not abolish the increased risk of severe infection [10, 11].

The spleen has an extensive circulation of branches from gastric, omental, and pancreatic arteries. The short gastric vessels are terminal branches of the left gastroepiploic artery. They supply the gastric cardia, gastric fundus, and spleen, and lack a collateral network so that parts of the spleen may easily become ischemic if one of the branches is injured. Ischemia can be diagnosed during surgery if there is a change in color, especially of the upper pole of the spleen [9]. It is difficult to assess the extent of ischemic damage of the spleen as only its surface can be seen during surgery and it cannot be followed-up post-operatively. We have arbitrarily chosen to assess the splenic size 3 months after surgery. At this time point, splenic infarction with a decrease in size, if present, should be visible. Serial ultrasonographic measurements at different time points after surgery were not considered necessary, as it is highly probable that the remaining arterial branches of the spleen will prevent a further decrease in size after the period of 3 months.

In this group of patients we have shown that a change of color up to $50 \%$ is not associated with relevant splenic atrophy. This confirms the existing opinion that that discoloration alone lacks a clinical relevance in the majority of the patients [8]. In adults, the prevalence of pathologically proven infarction after fundoplication is less than $1 \%$ [19]. However, the incidence in children is unknown. A large polar infarction may lead to a substantial decrease in splenic size and so to an increased morbidity or even mortality [8, 9]. Symptoms of splenic infarction may be subtle, and include left upper quadrant abdominal pain, changes in appetite, and early satiety, of which the third is common after fundoplication. Fever and an elevated white blood cell count are aspecific symptoms which can be present in ischemia but also in infection and other disorders [19-21].

The differences between pre- and post-operative ultrasound measurements of the spleen are relatively small, and include both an increase and decrease in size. This may be explained by inter-observer variability and a changed position of the spleen. Furthermore, as the measurements in seven patients were done more than 6 months after surgery, natural growth of the spleen may be partly responsible for the post-operatively measured increased ratios. The lowest ratio of the pre and post-operative ultrasonographic splenic size measurements was 0.67 , which is well above the size which is considered necessary for an adequate immunologic function. Moreover, there was no correlation between the intra-operatively estimated perfusion defects of the spleen and decrease of splenic size after surgery. Therefore, we conclude that discoloration of the spleen after division of the short gastric vessels is not associated with a significant post-operative decrease in splenic size. However, due to the relatively limited number of included patients, it cannot be fully excluded that splenic atrophy after division of the short gastric vessels in Nissen fundoplication never occurs.

Open Access This article is distributed under the terms of the Creative Commons Attribution Noncommercial License which permits any noncommercial use, distribution, and reproduction in any medium, provided the original author(s) and source are credited.

\section{References}

1. Driessen C, Verhoeven BH, Ten WE et al (2010) Does laparoscopy lower the threshold for the surgical treatment of gastroesophageal reflux disease in children? J Pediatr Gastroenterol Nutr 51:599-602

2. Lobe TE (2007) The current role of laparoscopic surgery for gastroesophageal reflux disease in infants and children. Surg Endosc 21:167-174 
3. Nelson SP, Chen EH, Syniar GM et al (1997) Prevalence of symptoms of gastroesophageal reflux during infancy. A pediatric practice-based survey. Pediatric Practice Research Group. Arch Pediatr Adolesc Med 151:569-572

4. Donahue PE, Samelson S, Nyhus LM et al (1985) The floppy Nissen fundoplication. Effective long-term control of pathologic reflux. Arch Surg 120:663-668

5. Huntington TR, Danielson L (2001) Variation in fundic dimensions with respect to short gastric vessel division in laparoscopic fundoplication. Surg Endosc 15:76-79

6. O'Boyle CJ, Watson DI, Jamieson GG et al (2002) Division of short gastric vessels at laparoscopic nissen fundoplication: a prospective double-blind randomized trial with 5-year follow-up. Ann Surg 235:165-170

7. Watson DI, Pike GK, Baigrie RJ et al (1997) Prospective doubleblind randomized trial of laparoscopic Nissen fundoplication with division and without division of short gastric vessels. Ann Surg 226:642-652

8. Martinez DG, Sanchez AW, Garcia AP (2008) Splenic abscess after laparoscopic Nissen fundoplication: a consequence of short gastric vessel division. Surg Laparosc Endosc Percutan Tech $18: 82-85$

9. Wilkinson NW, Edwards K, Adams ED (2003) Splenic infarction following laparoscopic Nissen fundoplication: management strategies. Jsls 7:359-365

10. Melles DC, de Marie S (2004) Prevention of infections in hyposplenic and asplenic patients: an update. Neth J Med 62:45-52

11. William BM, Corazza GR (2007) Hyposplenism: a comprehensive review. Part I: basic concepts and causes. Hematology $12: 1-13$
12. Dijkman KP, van Heurn LW, Leroy PL et al (2009) Vanishing spleen after Nissen fundoplication: a case report. Eur J Pediatr 168:355-357

13. Gold BD (2004) Gastroesophageal reflux disease: could intervention in childhood reduce the risk of later complications? Am J Med 117(Suppl 5A):23S-29S

14. Mardani J, Lundell L, Lonroth $\mathrm{H}$ et al (2009) Ten-year results of a randomized clinical trial of laparoscopic total fundoplication with or without division of the short gastric vessels. Br J Surg 96:61-65

15. Rothenberg SS (2005) The first decade's experience with laparoscopic Nissen fundoplication in infants and children. J Pediatr Surg 40:142-146 (discussion 147)

16. Di Lorenzo C, Orenstein S (2002) Fundoplication: friend or foe? J Pediatr Gastroenterol Nutr 34:117-124

17. Hassall E (2005) Outcomes of fundoplication: causes for concern, newer options. Arch Dis Child 90:1047-1052

18. Castagnola E, Fioredda F (2003) Prevention of life-threatening infections due to encapsulated bacteria in children with hyposplenia or asplenia: a brief review of current recommendations for practical purposes. Eur J Haematol 71:319-326

19. Nores M, Phillips EH, Morgenstern L, Hiatt JR (1998) The clinical spectrum of splenic infarction. Am Surg 64:182-188

20. Jaroch MT, Broughan TA, Hermann RE (1986) The natural history of splenic infarction. Surgery 100:743-750

21. O'Keefe JH Jr, Holmes DR Jr, Schaff HV, Sheedy PF 2nd, Edwards WD (1986) Thromboembolic splenic infarction. Mayo Clin Proc 61:967-972 